\title{
Fear of blushing: the role of the expected influence of displaying a blush on others' judgements.
}

Citation for published version (APA):

de Jong, P. J., Peters, M. L., Dijk, C., Nieuwenhuis, E., Kempe, H., \& Oelerink, J. (2006). Fear of blushing: the role of the expected influence of displaying a blush on others' judgements. Cognitive Therapy and Research, 30, 623-634. https://doi.org/10.1007/s10608-006-9040-y

Document status and date:

Published: 01/01/2006

DOI:

10.1007/s10608-006-9040-y

Document Version:

Publisher's PDF, also known as Version of record

Document license:

Taverne

Please check the document version of this publication:

- A submitted manuscript is the version of the article upon submission and before peer-review. There can be important differences between the submitted version and the official published version of record.

People interested in the research are advised to contact the author for the final version of the publication, or visit the DOI to the publisher's website.

- The final author version and the galley proof are versions of the publication after peer review.

- The final published version features the final layout of the paper including the volume, issue and page numbers.

Link to publication

\footnotetext{
General rights rights.

- You may freely distribute the URL identifying the publication in the public portal. please follow below link for the End User Agreement:

www.umlib.nl/taverne-license

Take down policy

If you believe that this document breaches copyright please contact us at:

repository@maastrichtuniversity.nl

providing details and we will investigate your claim.
}

Copyright and moral rights for the publications made accessible in the public portal are retained by the authors and/or other copyright owners and it is a condition of accessing publications that users recognise and abide by the legal requirements associated with these

- Users may download and print one copy of any publication from the public portal for the purpose of private study or research.

- You may not further distribute the material or use it for any profit-making activity or commercial gain

If the publication is distributed under the terms of Article $25 \mathrm{fa}$ of the Dutch Copyright Act, indicated by the "Taverne" license above, 


\title{
Fear of Blushing: The Role of the Expected Influence of Displaying a Blush on Others' Judgements
}

\author{
Peter J. de Jong · Madelon L. Peters · Corine Dijk • \\ Eveline Nieuwenhuis $\cdot$ Henk Kempe $\cdot$ Julia Oelerink
}

Published online: 18 November 2006

(C) Springer Science+Business Media, Inc. 2006

\begin{abstract}
Objectives To explain blushing phobics' fearful preoccupation with blushing, this study investigated the anticipated consequences of displaying a blush on others' judgements of the self and of the incident. We tested whether especially in the context of ambiguous situations that may be interpreted as a transgression, individuals would expect negative consequences of their blushing, and whether this effect is most pronounced in relatively high blushing fearful individuals.

Design and method Using a vignette approach, participants $(N=36)$ with variable levels of blushing fear were instructed to imagine that they did or did not started blushing (i) after a mishap and (ii) in situations that are more ambiguous in their meaning.

Results Independent of situation, participants indicated to expect a positive rather than a negative influence of blushing on others' judgements of the self and of the incident. Unexpectedly, this pattern was even most pronounced in relatively fearful individuals.

Conclusion The results are in conflict with the idea that fear of blushing is fuelled by overestimating the undesirable communicative effects of blushing in ambiguous situations. In addition, the results seem to imply that different processes are involved in judging blushing others and judging other's views of themselves when displaying a blush.
\end{abstract}

\section{P. J. de Jong (凶)}

Department of Clinical and Developmental Psychology, University of Groningen, Grote

Kruisstraat 1/2, 9712 TS Groningen, The Netherlands

e-mail: p.j.de.jong@rug.nl

\section{L. Peters}

Department of Medical, Clinical, \& Experimental Psychology, Maastricht University, Maastricht, The Netherlands

C. Dijk $\cdot$ E. Nieuwenhuis $\cdot$ H. Kempe $\cdot$ J. Oelerink

Department of Clinical and Developmental Psychology, University of Groningen, Groningen,

The Netherlands 
Keywords Blushing $\cdot$ Fear of blushing $\cdot$ Social phobia $\cdot$ Judgemental bias $\cdot$ Metaperception · Appeasement

By now there is considerable evidence that displaying a blush may have face-saving qualities. A series of studies using a vignette approach showed that blushing after a mishap (e.g., spilling coffee on other's clothings) or a voluntary transgression (e.g., damaging someone else's flowerbed) attenuated the attributed seriousness of the incident as well as the negative impression of the actor (de Jong, 1999; de Jong, Peters, \& De Cremer, 2003). Adding to the validity of these findings, similar results have been found in the context of actual rather than hypothetical interactions (Smits, 2003). Yet, recent research showed that these desirable effects of the blush on other's judgements are restricted to situations in which the actors display unambiguously deviant behaviours. In an experiment using a vignette approach (de Jong et al., 2003) as well as in a study testing participants' reactions to actual blushing in social interactions (de Jong, Peters, De Cremer, \& Vranken 2002; Smits, 2003), we found blushing to have adverse effects in the context of more ambiguous behaviours that may be interpreted as a transgression. In such an ambiguous context blushing was interpreted as signalling that the event should be taken as an intentional transgression rather than an innocent coincidence. Thus, in the absence of a clear-cut mishap/transgression/predicament, observers may interpret the blush as evidence that the blusher has behaved in a socially inappropriate manner (cf. Leary, Landel, \& Patton, 1996).

Thus far studies on the interpersonal signalling functions of the blush and other displays of embarrassment or shame focussed on the influence of these expressions on the observer's appreciation of the actor (e.g., de Jong, 1999; de Jong et al., 2003; Keltner, 1995; Keltner, Young, \& Buswell, 1997; Semin \& Manstead, 1982). However, it seems reasonable to assume that the alleged functional properties of the blush also affect the actor's expectations about the observer's judgements. Following this, it has been argued that blushing fearful individuals' fear of blushing may, at least partly, be due to a tendency to overestimate the negative influence of their blushing on other people's judgments (e.g., de Jong et al., 2003).

In a first attempt to explore the influence of displaying a blush on actors' expectations of others' judgements, blushing fearful and explicitly non-fearful participants were presented with a series of vignettes some of which referred to apparently involuntary mishaps, and some to ambiguous situations that could be interpreted as a transgression (de Jong \& Peters, 2005). As in previous vignette-studies investigating the influence of blushing on the observer's appreciation of the actor (de Jong, 1999; exp. 1 \& 2; de Jong et al., 2003; exp. 1 \& 2), in half of the vignettes it was mentioned that the actors displayed a blush response following the incident, whereas in the other half of the vignettes this particular information was omitted. Participants were prompted in the perspective of the (blushing) actor and were asked to indicate their beliefs about the impressions they conveyed to hypothetical others. Unexpectedly, participants' expectations of the observers' judgements in these hypothetical situations appeared independent of their blushing (de Jong \& Peters, 2005). Contrasting with the results of a series of studies showing that others' judgements of the actor are in fact strongly influenced by the absence/presence of a blush (e.g., de Jong et al., 2003), neither high nor low fearful individuals appeared to anticipate that blushing in ambiguous social situations might adversely influence others' judgements of themselves (or positively in the context of a mishap). 
The absence of any effect of displaying a blush on the actors' expectations of others' judgements seem to refute the idea that the expected effects of displaying a blush in these situations might play an important role in blushing fearful individuals' fear of blushing. However, at least two testable explanations can be put forward to explain the apparent absence of any effect of displaying a blush on the actors' beliefs about the observers' judgements in this previous study.

First, it cannot be ruled out that the absence of any effect of blushing might have been due to the particular experimental manipulation that was used. The manipulation consisted of inserting or omitting a statement about the actor displaying a blush. Yet, merely omitting the information that the actor (i.e., participant) blushed does not prevent participants from assuming that blushing did occur. Therefore, it cannot be ruled out that participants expected or implied to blush in all of the awkward social situations that were described in the vignettes, irrespective of whether this was mentioned or not. If, indeed, participants did assume that they would blush in situations that were described in the (control) vignettes, which did not explicitly mention that the actor displayed a blush, this would have undermined the blush manipulation that was used in that study. Since blushing fearful individuals typically believe that that they will blush easily (e.g., Bögels, Alberts \& de Jong, 1996; Mulkens, de Jong, Dobbelaar \& Bögels, 1999), they might be especially prone to make such inferences, thereby further undermining the sensitivity of the original approach to find differential effects between high and low fearful individuals.

Second, the absence of any effect of displaying a blush on the actors' expectations of others' judgements in this previous study may reflect important discrepancies between the processes involved in judging others (e.g., de Jong et al., 2003) and in judging others' views of the self (e.g., de Jong \& Peters, 2005). There is ample evidence that people, when judging others, typically infer that current behaviours reflect the true person/goal/ intention (fundamental attribution error, Jones \& Davis, 1965). Thus the impression people actually convey to others does strongly depend on their current behaviours. Meanwhile, a series of recent studies showed that, when considering the judgements that others form of themselves (i.e., meta-perceptions), people typically ignore/underestimate the impact of their current behaviours and exaggerate the extent to which their true self will be evident to others (e.g., Vorauer, 2001; Vorauer \& Miller, 1997; exp. 2). Following this, similar processes might have led participants in this previous study to ignore their blushing when considering the judgement that others would form of them. However, even if people may ignore the influence of their blushing on others' views of the self when being involved in a particular social interaction (cf. Vorauer, 2001), they may still have strong ideas about the influence of displaying a blush when they explicitly reflect on past or future interactions. Yet, participants in this previous study were not explicitly invited to consider the consequences of the presence or absence of blushing in the situations that were described in the vignettes. Hence, the previous results are silent with respect to the possibility that people do anticipate an effect of their blushing on others' judgements when they explicitly consider the impact of displaying a blush (e.g., when reconsidering past interactions or when anticipating future interactions). Therefore, it might still well be that fearful individuals do overestimate the negative consequences of their blushing when they are explicitly instructed to consider the impact of displaying a blush on others' judgements.

All in all, since there are serious reasons to believe that the absence of any effect of blushing in this previous study of de Jong and Peters (2005) might have been due to the particular blush manipulation that was used, it seems premature to discard the 
possibility that blushing fearful individuals do overestimate the negative influence of their blushing. Therefore, the present study tested whether blushing fearful individuals do exaggerate the negative consequences of their blushing when they are explicitly asked to consider the influence of displaying a blush on others' judgements. The present study used a manipulation that provided an unambiguous contrast to evaluate the anticipated influence of displaying a blush on others' judgements. Rather than inserting/ omitting a statement indicating that the actor displayed a blush, participants in the present experiment were explicitly asked to imagine that they did or did not display a blush in a particular situation. Clearly, this procedure prevented participants from making the spontaneous inference that blushing might (also) have occurred in the control situations. As in the previous studies (e.g., de Jong et al., 2003; de Jong \& Peters, 2005), two categories of vignettes were used: situations describing prototypical mishaps and more ambiguous social situations that observers may interpret as a transgression but not necessarily so.

We anticipated that in the present experimental set-up participants would generally expect a favourable effect of displaying a blush in the context of clear-cut mishaps, but undesirable negative effects in the context of ambiguous social situations. Most pertinent to our research question we anticipated that this latter effect would vary as a function of blushing fear (i.e., being most pronounced in relatively fearful individuals).

\section{Method}

\section{Participants}

Participants $(N=36)$ were an unselected sample recruited by 3 undergraduate psychology students from the University of Groningen who carried out this study as a partial fulfilment of the requirements for a Master's degree. Participants were recruited among visitors of the university mess and the university library, as well as among family members and friends (of friends) of these students. There were no family members within the present sample. To optimise comparability with the previous study of de Jong and Peters (2005) we restricted our sample to female participants. All participants were fair-skinned (which is the default in this part of the Netherlands). Mean age was 24.3 years (range 17-35 years). Mean level of education was 7.4 on a scale ranging from 1 (only primary education, which roughly corresponds to 6 years of education) to 8 (university degree, which corresponds to at least 16 years of education).

\section{Assessment}

The blushing subscale of the Blushing Trembling and Sweating Questionnaire (BTSQ; Bögels \& Reith, 1999) was used to assess individual differences in fear of blushing. The BTSQ has been shown to be a reliable instrument in terms of internal consistency and test-retest reliability. In addition, the subscales of the BTSQ have been shown to have good discriminant validity; it is able to discriminate social phobic individuals from controls, as well as social phobics with fear of blushing from social phobics without such fear (Bögels \& Reith, 1999). For a more comprehensive description of the sample, participants also completed the 12-item version of the Fear of Negative Evaluation Scale (FNE; Leary, 1983), and the social phobia subscale of the Fear Questionnaire 
Table 1 Description of the sample and correlations between measures

\begin{tabular}{lllll}
\hline & Mean (SD) & Range & Brief FNE & FQ \\
\hline BTSQ (0-100) & $34.1(25.5)$ & $0-91$ & .27 & $.34^{*}$ \\
FQ (0-40) & $10.5(6.4)$ & $0-24$ & $.34^{*}$ & - \\
Brief FNE (0-48) & $21.8(7.9)$ & $3-41$ & - & - \\
\hline
\end{tabular}

$* P<.05$

Note : BTSQ = Blushing, Trembling, and Sweating Questionnaire; for the purpose of the present study we only used the blushing subscale; FNE = Fear of Negative Evaluation; FQ Fear Questionnaire (Social Phobia subscale)

(FQ; Marks \& Mathews, 1979) (see Table 1). As can be seen in Table 1, participants' BTSQ scores showed considerable variation and covered almost the entire scale. Consistent with previous research (e.g., Bögels, Alberts, \& de Jong, 1996; Neto, 1996) fear of blushing was found to be associated with social anxiety as indexed by the social phobia subscale of the FQ (see Table 1). A similar association was evident with FNE scores although this correlation did not reach the conventional level of significance. The modest correlations between indices of social anxiety and fear of blushing sustain the validity of differentiating between fear of blushing and the more general concept of social anxiety (cf. Bögels \& Reith, 1999).

\section{Materials and measures}

We used a paper and pencil task, which consisted of a series of vignettes ${ }^{1}$. The social events that were described in the present vignettes were similar to those that were successfully employed in previous work (de Jong et al., 2003; de Jong \& Peters, 2005). We made some minor changes since some situational details of the previously used vignettes were specifically tailored for students of Maastricht University. Participants were prompted in the perspective of the actor and were asked to indicate how they would think the observing other would evaluate the situation on several dimensions (see below). To test the anticipated influence of displaying a blush in particular situations, in half of the vignettes participants were explicitly asked to imagine that they displayed a blush in this particular situation. Since there is evidence that the visibility of blushing influences the nature of emotions experienced in social encounters (Drummond \& Lim, 2000), and people may vary in their spontaneous inferences with respect to the (in)visibility of their blushing we used the following wording: "Imagine that you start blushing visibly in this situation". In the other half of the vignettes participants were explicitly asked to imagine that they did not start blushing in this particular situation ("Imagine that you don't start blushing in this situation").

The vignettes referred to two different categories of social situations. One category consisted of a typical mishap (e.g., spilling coffee on someone's trousers while pouring out coffee from a thermos jug in a crowded train), and one consisted of social situations in which an actor behaves in good faith within the context of an ambiguous situation that could be erroneously interpreted by others as a transgression (e.g., the actor posits his/her bag near the dozens of other bags that were already left by some other students; when leaving the library, the actor accidentally takes someone else's bag and is then accosted by the actual owner of the bag). So there were 4 different types of vignettes

\footnotetext{
${ }^{1}$ The vignettes that were used in this study can be obtained upon request from the first author.
} 
following from the present 2 Category (mishap versus ambiguous situation) $\times 2$ Actor's Response (blush versus no blush) design. For both categories of social situations we used 3 different (but conceptually similar) incidents to cancel out the influence of particular contexts. Each of the three incidents was used equally often as the representation of a particular social situation (i.e., this was balanced across participants).

Participants were presented with a series of 4 vignettes (one of each type); for each series a particular incident appeared only once. To minimise the influence of carry-over effects, the order of the 4 types of vignettes was randomised for each participant. The vignettes were printed on 4 separate sheets. On the cover page participants were instructed that this experiment concerned an investigation into the appraisal of events and they were asked to identify themselves with the description as much as possible.

Each vignette was followed by four $100 \mathrm{~mm}$ Visual Analogue Scales (VASs). The VASs that we used in the present study were similar to the scales that were used in the previous study of de Jong and Peters (2005). VAS-1 indexed the alleged revealing properties of the blush and asked participants to indicate the probability that the other person would think that the incident reflected a deliberate social transgression (e.g., "What is in your view the probability that this other student believes that you took her bag deliberately?", $0=0 \%, 100=100 \%$ ). Note in passing that there is a subtle difference between the implications of high probability ratings in the mishap versus the ambiguous condition (see also de Jong et al., 2003). In the latter, the probability ratings reflect to what extent participants expect the other to interpret the situations as reflecting an innocent coincidence or as a deliberate transgression. In the former, the probability ratings do not so much reflect whether or not the situation is expected to be interpreted as an accident but to what extent the accident is expected to be interpreted as reflecting a deliberate act.

VAS-2 asked participants to indicate their expectancies about the other's evaluation of the situation (e.g., "How seriously do you think the other student will judge this situation", $0=$ not serious at all, $100=$ very serious.) VAS-3 asked participants to indicate their expectancies about the other's evaluation with respect to the participant's reliability (e.g., "How reliable do you think the other student will judge you", $0=$ not at all reliable, $100=$ very reliable). Finally VAS-4 asked participants to indicate their expectancies about the other's evaluation with respect to their likeability (e.g., "How much do you think the student will like you", $0=$ very unlikeable, $100=$ very likeable). It was stressed that there were no right or wrong answers and that only their personal judgement counted. Participants were tested individually.

\section{Data reduction and analysis}

To test the influence of displayed response (blush versus no blush) as a function of situation (mishap versus ambiguous) and participants' fear of blushing, each of the four dependent variables (intentionality, seriousness of incident, reliability, likeability) were subjected to a multi-level regression analysis (using the program MLwiN; see http:// multilevel.ioe.ac.uk/index.html) with 'measurements within participants' and 'participants' being the relevant levels here. Before running the analyses, we computed a dummy variable for Situation $(0=$ mishap, $1=$ ambiguous $)$ and a dummy for Response (no blush $=0$, blush $=1$ ). Predictors were selected on the basis of the present 2 by 2 design together with participants' individual differences in fear of blushing. For each of the dependent variables we tested the following regression equation: 


$$
\begin{aligned}
y_{\mathrm{ij}=} & \beta_{0} \text { Constant }+\beta_{1} \text { Situation }+\beta_{2} \text { Response }+\beta_{3} \mathrm{BTSQ}+\beta_{4} \text { Situation } * \text { Response } \\
& +\beta_{5} \text { Situation } * \mathrm{BTSQ}+\beta_{6} \text { Response } * \mathrm{BTSQ}+\beta_{7} \text { Situation } * \text { Response } * \mathrm{BTSQ}+\varepsilon_{\mathrm{ij}}
\end{aligned}
$$

In this equation 'Constant' denotes the intercept (average of the VAS scores for a particular variable when no other predictors are taken into account), and ' $\epsilon_{\mathrm{ij}}$ ' denotes residual variance that cannot be explained by the predictors that were included in the equation. Accordingly, we investigated the contribution of (i) the main factors in the design as well as their interaction, (ii) the main factors and their interaction term as a function of blushing fear; (iii) individual differences in fear of blushing irrespective of situation and displayed response. For all variables we started with the full equation. Via stepwise deletion of the non-significant predictors we eventually arrived at the final equation (i.e., the equation most efficiently defining the target variable).

\section{Results}

For each of the dependent variables (intentionality, seriousness, reliability, likeability) mean scores of participants' responses on the VASs are summarised in Table 2 as a function of Situation (mishap versus ambiguous) and Response (blush versus no blush).

\section{Attributed intentionality}

For attributed intentionality the multi-level regression analysis resulted in the following parameter (and error) estimations of the final equation: $\beta_{0 \mathrm{i}}$ constant +27.08 (4.09) Situation $+-.29(.08)$ Response*BTSQ with $\beta_{0 \mathrm{i}}$ constant $=43.55(3.22)+\mathrm{e}_{0 \mathrm{ij}}$. This result indicates that only the factor Situation and the interaction term of Response*BTSQ significantly contributed to the equation. The positive $\beta$ of Situation indicates that in line with the experimental manipulation, participants considered it more probable that others would take the incident in the ambiguous situation as resulting from an intentional act, than the incident in the mishap situation. The negative $\beta$ of the Response*BTSQ interaction term indicates that the higher participants' fear of blushing the stronger they believed that blushing would generally lower the levels of attributed intentionality. The situation* response*BTSQ interaction term did not contribute significantly to the model, so the influence of fear of blushing was similar for both types of situations.

Table 2 Means (SD) of actor's judgements of others' view with respect to attributed intentionality and seriousness of the incident and their dispositions in the context of mishaps and ambiguous events as a function of displayed response (blush versus no blush)

\begin{tabular}{llllll}
\hline & \multicolumn{2}{l}{ Mishap } & & \multicolumn{2}{l}{ Ambiguous } \\
\cline { 2 - 3 } \cline { 5 - 6 } & Blush & No blush & & Blush & No blush \\
\hline Intentionality & $16.08(15.89)$ & $26.64(32.73)$ & & $43.89(28.29)$ & $53.00(31.10)$ \\
$\begin{array}{l}\text { Seriousness } \\
\text { Dispositions }\end{array}$ & $42.56(25.39)$ & $54.31(26.46)$ & & $45.33(28.46)$ & $53.39(30.78)$ \\
$\begin{array}{l}\text { Reliability } \\
\text { Likeability }\end{array}$ & $59.50(22.01)$ & $49.53(23.49)$ & & $46.39(27.31)$ & $41.75(29.80)$ \\
\hline & $43.47(21.98)$ & $33.81(24.46)$ & & $41.53(25.77)$ & $39.00(26.07)$ \\
\hline
\end{tabular}


Seriousness of incident

Multi-level regression analysis resulted in the following equation: $\beta_{0 \mathrm{i}}$ constant +-.37 (.09) Response*BTSQ, with $\beta_{0 \mathrm{i}}$ constant $=42.52(2.74)+\mathrm{e}_{0 \mathrm{ij}}$. These parameter estimations show that only the Response*BTSQ interaction term contributed significantly to the equation. The negative $\beta$ of the Response*BTSQ interaction term indicates that the higher participants' level of blushing fear, the stronger they believed that displaying a blush would lower the attributed seriousness of the incident/mishap. The absence of the Response*Situation*BTSQ interaction term in the final equation indicates that this anticipated (favourable) effect of the blush as a function of blushing fear was similar for both types of situations.

\section{Dispositional characteristics}

\section{Reliability}

Multi-level regression analysis resulted in the following final equation: $\beta_{0 \mathrm{i}}$ constant + -10.44 (3.89) Situation +7.30 (3.88) Response, with $\beta_{0 \mathrm{i}}$ constant $=47.72(3.78)+\mathrm{e}_{0 \mathrm{ij}}$. This indicates that the factor Situation contributed significantly to the equation, whereas the contribution of the factor Response came close to significance. The negative $\beta$ of Situation indicates that people generally anticipated higher reliability ratings in the mishap situation than in the ambiguous situation. The positive $\beta$ of Response indicates that, if anything, participants anticipated a positive effect of displaying a blush (i.e., being judged as a more reliable person). As can be concluded from the composition of the final equation, both effects were independent of individual differences in fear of blushing.

\section{Likeability}

Multi-level regression analysis resulted in the following final equation: $\beta_{0 \mathrm{i}}$ constant +.19 (.08) Response*BTSQ, with $\beta_{0 \mathrm{i}}$ constant $=42.76(2.82)+\mathrm{e}_{0 \mathrm{ij}}$. This pattern of parameter estimations indicate that only the Response*BTSQ interaction term contributed significantly to the equation. The positive $\beta$ of the Response*BTSQ interaction term indicates that the higher the level of fear of blushing the more positive the anticipated influence of displaying a blush.

\section{Discussion}

The overall pattern of results indicates that in the context of hypothetical situations referring to prototypical mishaps as well as to situations that are more ambiguous in their meaning, individuals generally expect a desirable influence of displaying a blush on other's judgement of the self. More specifically it was found that individuals anticipated that displaying a blush (i) will lower the probability that others interpret their behaviour as an intentional transgression; (ii) result in others judging the incident as less serious, and (iii) result in a relatively positive appreciation of their likeablity. There was a tendency in the same direction for the influence of blushing on the anticipated judgement of their reliability. The results indicate that apart from the anticipated reliability 
judgements, the anticipated desirable effects were most pronounced in participants with relatively high levels of blushing fear.

The present study was designed to test whether blushing fearful individuals overestimate the undesirable revealing effects of their blushing when they are explicitly asked to consider the influence of displaying a blush on others' judgements. Yet, in contrast to our predictions, and at odds with previous research showing that others' judgements of the actor are in fact adversely influenced by displaying a blush in ambiguous situations (e.g., de Jong et al., 2002, 2003), participants generally indicated to expect a favourable effect of their blushing irrespective of the type of situation. This tendency to expect a favourable effect of blushing was found to be most pronounced in relatively fearful individuals: The higher individuals' fear of blushing, the more desirable the anticipated influence of displaying a blush. Although it is not immediately evident why relatively fearful individuals expected a relatively strong favourable influence of displaying a blush in the present hypothetical situations, the pattern of results is difficult to reconcile with the idea that an overestimation of the revealing effects of the blush in ambiguous situations plays an important role in generating fear of blushing.

The general finding that participants expected a positive influence of their blushing in a mishap situation is consistent with the actual influence of displaying a blush on the observers' judgements in such situations (e.g., de Jong, 1999). A testable explanation of why participants (also) expected a positive influence of their blushing in the context of ambiguous situations might be that they anticipated that irrespective of displaying a blush, others would be liable to interpret their behaviour in the ambiguous vignettes as reflecting a transgression rather than a coincidence. If indeed participants anticipated that others would interpret the ambiguous situations as reflecting a clear-cut transgression, blushing may be expected to be interpreted by observers as signifying the participant's recognition that she has committed a social infraction and sincerely regrets it (cf. Castelfranchi \& Poggi, 1990). In its turn such an interpretation will attenuate the negative interpretation of the incident compared to similar situations in which the actor did not display a blush, and may adjust the impression that the transgression reflects a fully intentional act (e.g., de Jong et al., 2003; exp 2). It seems reasonable to assume that the tendency to believe that others are liable to interpret their behaviour as reflecting clear-cut deviant behaviour would be most pronounced in relatively fearful individuals. This then may explain the relatively positive expectations of displaying a blush in relatively high fearful individuals. One way to test this possibility in future research would be to separately assess the anticipated interpretation of the incident (i.e., the probability that it reflects a transgression) on the one hand, and the attributed intentionality of the actor's behaviours on the other (cf. de Jong et al., 2003: exp 1 versus exp 2). Yet, irrespective of the outcome of such a study, the present pattern of findings is clearly at odds with the idea that misjudging the communicative value of blushing in this type of ambiguous situations plays a pivotal role in blushing phobia.

In contrast to the present results, a previous study using a similar approach failed to find blushing to influence the anticipated judgement of others (de Jong \& Peters, 2005). Yet, rather than explicitly inviting participants to consider the impact of displaying a blush on others' judgements, that earlier study used a more implicit blush manipulation. In half of the vignettes it was mentioned that the actors (i.e., the participants) displayed a blush, whereas in the other half of the vignettes this particular information was omitted. Obviously, merely omitting that the actor blushed, does not 
prevent participants from assuming that blushing did occur irrespective of whether this was mentioned or not. If indeed participants in that earlier study would have implied to blush irrespective of whether this was explicitly mentioned or not, this might explain the absence of a difference between the blush and the no-blush conditions. However, the concurrent finding in that previous study that independent of condition (i.e., blush versus no-blush) high fearful individuals generally reported more negative expectations of others' judgements than low fearful individuals, renders this explanation very unlikely in the light of the present results indicating that when using an unambiguous contrast to evaluate the anticipated influence of displaying a blush, people with relatively high fear levels expected relatively positive rather than negative influences of their blushing. Therefore, a more convincing explanation would be that participants in this earlier study simply ignored the blush when considering the judgements that others form of themselves.

Such an interpretation would be consistent with the general tendency of people to ignore the impact of their current behaviours and to exaggerate the extent to which their true self will be evident to others when reflecting on others' judgement of themselves (e.g., Vorauer, 2001; Vorauer \& Miller, 1997; exp. 2). Meanwhile, the present study suggests that people do anticipate an effect of their blushing when they are explicitly invited to reflect on the impact of displaying a blush on others' judgements. So even if people may ignore the influence of their blushing on others' views of the self when being involved in a particular social interaction, they may still have strong ideas about the influence of displaying a blush when they explicitly reflect on past or future interactions. However, since the present results indicate that under such conditions even fearful individuals generally expect favourable rather than socially threatening effects of displaying a blush, these findings add to the previous work of de Jong and Peters (2005) in casting serious doubts on the idea that fear of blushing reflects a tendency to exaggerate the negative consequences of blushing.

Meanwhile, it might still be that fearful individuals do exaggerate the negative consequences of blushing in other types of situations. For example, it has been argued that under particular conditions blushing may expose ones private thoughts or particular dispositional characteristics (Crozier, 2001, 2004). Following this, it would be interesting to see in future research whether perhaps fear of blushing essentially reflects a fearful preoccupation with the idea that blushing in the absence of a straightforward elicitor may unwantedly reveal particular characteristics (e.g., nervousness, incompetence) or private thoughts, which in turn may pose a threat to the blusher's public self-image.

Some comments are in order with respect to the methodology of the present study. First, in line with the earlier study of de Jong and Peters (2005), the present study relied exclusively on female participants. Therefore, it cannot be ruled out that different results would have been obtained in a mixed sample. Yet, although there is evidence that women report generally a higher blushing propensity than men (e.g., Bögels, Alberts, \& de Jong, 1996), there seem no obvious a priori reasons to suspect that the influence of the current manipulation would be fundamentally different between men and women. Second, since the recruitment of participants was not entirely random, it cannot be ruled out that some form of selection bias might have influenced the present results.

Third, although the present blush manipulation "imagine that you start blushing visibly" is unambiguous with respect to the visibility of the blush, it still allows participants to envision blushing in a great variety of shades. Since people may 
attribute a different meaning to blushing lightly and blushing deeply, this feature might have influenced our findings. However, it seems not very plausible to assume that within participants the interpretation of the blush manipulation (in terms of the envisioned darkness of the shade) systematically varied across mishaps and ambiguous situations. Therefore, it seems unlikely that this aspect had a major impact on the general pattern of results. Meanwhile, it should be acknowledged that there is evidence that blushing fearful individuals tend to overestimate the intensity of their blushing (e.g., Mulkens et al., 1999). Following this, one could speculate that in the present context relatively high fearful individuals envisaged their blushing as relatively dark shaded and that it is this overestimation of the intensity of their blushing that constitutes their relatively positive outcome expectancies of displaying a blush. However, even if this would have been the case, this would still imply that (also) high fearful individuals are characterised by positive rather than negative expectations of displaying a (deep) blush on others' judgements.

Finally, it should be stressed that the present study relied on vignettes rather than actual interactions, and thus relied upon hypothetical situations and hypothetical responses. Obviously, such an approach has limitations as the functions of the blush response in real-life situations may not fully correspond with its functions in imagined situations (e.g., Parkinson \& Manstead, 1993). In addition, such an approach relies upon participants' ability to accurately report on how they would react, and one may question whether individuals are indeed (always) able to do so. For example, it might be that blushing fearful individuals are not fully aware of the fact that they overestimate the revealing effects of their blushing in actual social interactions and thus tend to respond otherwise in the context of a vignette study. Clearly then, the present findings should be interpreted with care. To arrive at more solid conclusions it would be important for future research to test individuals in actual rather than hypothetical social interactions (cf. de Jong et al., 2002). In addition, because the relevant cognitions are not necessarily accessible to introspection it would be important to complement self report measures of the anticipated judgement of others with indirect (e.g., behavioural) measures, which do not require introspection.

Following this, we are currently exploring whether in the context of actual social interactions, blushing fearful individuals act in a way as if they overestimate the revealing effects of their blushing. Previous experimental research showed that after a clear-cut predicament, participants typically engaged in alternative self-presentational tactics to improve their damaged social image when they were led to believe that the experimenter did not notice their blushing (Leary et al., 1996). If indeed people fear blushing because of its presumed revealing properties, one would predict that in an ambiguous context that can be interpreted as a transgression, participants will typically engage in remedial behaviours when they believe that relevant others did notice their blushing, to compensate for the undesirable revealing effects of being caught with a blush. To the extent that blushing fearful individuals implicitly overestimate the revealing effects of a blush, these effects will be especially pronounced in blushing fearful individuals.

Acknowledgments The authors are very grateful to Marieke Timmermans for her statistical advice and her assistance in analysing the data. The third author was supported by a fellowship of the Netherlands Organisation for Scientific Research (NWO, Grant No. 400-03-042). 


\section{References}

Bögels, S. M., Alberts, M., \& de Jong, P. J. (1996). Self-consciousness, self-focused attention, blushing propensity, and fear of blushing. Personality and Individual Differences, 21, 573-581.

Bögels S. M., \& Reith, W. (1999).Validity of two questionnaires to assess social fears: The Dutch Social Phobia and Anxiety Inventory and the Fear of Blushing, Trembling, and Sweating Questionnaire. Psychopathology and Behavioral Assessment, 21, 51-66.

Castelfranchi, C., \& Poggi I. (1990). Blushing as a discourse: Was Darwin wrong? In W. R. Crozier (Ed.), Shyness and embarrassment: Perspectives from social psychology. Cambridge: Cambridge University Press, pp. 230-251.

Crozier, W. R. (2001). Blushing and the exposed self: Darwin revisited. Journal for the Theory of Social Behavior, 31, 61-72.

Crozier, W. R. (2004). Self-consciousness, exposure, and the blush. Journal for the Theory of Social Behavior, 34, 1-17.

de Jong, P. J. (1999). Communicative and remedial effects of social blushing. Journal of Nonverbal Behavior, 23, 197-218.

de Jong, P. J., \& Peters, M. L. (2005). Do blushing phobics overestimate the undesirable communicative effects of their blushing? Behaviour Research and Therapy, 43, 747-758.

de Jong, P. J., Peters, M., \& De Cremer, D. (2003). Blushing may signify guilt: Revealing effects of blushing in ambiguous social situations. Motivation and Emotion, 27, 225-249.

de Jong, P. J., Peters, M., De Cremer, D., \& Vranken, C. (2002). Blushing after a moral transgression in a prisoner's dilemma game: Appeasing or revealing? European Journal of Social Psychology, 32, 627-644.

Drummond, P., \& Lim, H. K. (2000). Significance of blushing for fair- and dark-skinned people. Personality and Individual Differences, 29, 1123-1132.

Jones, E. E., \& Davis, K. E. (1965). From acts to dispositions: The attribution process in person perception. In L. Berkowitz (Ed.), Advances in experimental social psychology (vol 2). New York: Academic Press.

Keltner, D. (1995). Signs of appeasement: Evidence for the distinct displays of embarrassment, amusement, and shame. Journal of Personality and Social Psychology, 68, 441-454.

Keltner, D., Young, R. C., \& Buswell, B. N. (1997). Appeasement in human emotion, social practice, and personality. Aggressive Behavior, 23, 359-374.

Leary, M. (1983). A brief version of the Fear of Negative Evaluation Scale. Personality and Social Psychology Bulletin, 9, 371-375.

Leary, M. R., Landel J. L., \& Patton, K. M. (1996). The motivated expression of embarrassment following a self-presentational predicament. Journal of Personality, 64, 619-636.

Marks, I., \& Mathews, A. M. (1979). Brief standard self-rating for phobic patients. Behaviour Research and Therapy, 17, 263-267.

Mulkens, S., de Jong, P. J., Dobbelaar, A., \& Bögels, S. M. (1999). Fear of blushing: Fearful preoccupation irrespective of facial coloration. Behaviour Research and Therapy, 37, 1119-1128.

Mulkens S., Bögels S. M., de Jong P. J., \& Louwers, J. (2001). Fear of blushing: Effects of task concentration training versus exposure in vivo on fear and physiology. Journal of Anxiety Disorders, 15, 413-432.

Neto, F. (1996). Correlates of social blushing. Personality \& Individual Differences, 20, 365-373.

Parkinson, B., \& Manstead, A. S. R. (1993). Making sense of emotion in stories and social life. Cognition and Emotion, 7, 295-323.

Semin, G. R., \& Manstead, A. S. R. (1982). The social implications of embarrassment displays and restitution behavior. European Journal of Social Psychology, 12, 367-377.

Smits, A. (2003). True innocence doesn't need a blush, or does it? A study on the context dependency of the communicative and remedial effects of blushing in the context of a prisoner's deilemma game. Master's thesis, University of Maastricht.

Vorauer, J. D. (2001). The other side of the story: Transparency estimation in social interaction. In G. B. Moskowitz (Ed.), Cognitive Social Psychology. London: Lawrence Erlbaum.

Vorauer, J. D., \& Miller, D. T. (1997). Failure to recognize the effect of implicit social influence on the presentation of self. Journal of Personality and Social Psychology, 73, 281-295. 